\title{
VALUEABLE ACCOUNTING INFORMATION SPECIALIZATION OF FOOD BUSINESSES: AN EMPIRICAL INVESTIGATION OF ITS ANTECEDENTS AND CONSEQUENCE
}

\author{
Chairung Chaikambang, Kalasin Business School, Kalasin Rajabhat University,Thailand
}

dx.doi.org/10.18374/JIBE-13-2.3

\begin{abstract}
This research examines the effect of valuable accounting information specialization on decision making advantage in the new model. Whereas, best accounting system, accountant competency readiness and modern knowledge integration to become the antecedents of valuable information accounting specialization. The key research question is how valuable accounting information specialization affects decision making advantage. Data are collected from foods businesses in Thailand are the sample of the research. The regression analysis is employed to examine all hypotheses. The results indicate that valuable accounting information specialization has a positive effect on decision making advantage. Additionally, accountant competency readiness and modern knowledge integration definitely play an important role in explaining valuable accounting information specialization. A potential discussion of the results is evidently implemented in the research, contribution and conclusion of the research are presented accordingly.
\end{abstract}

Keywords: valuable accounting information specialization, best accounting system, accountant competency readiness, modern knowledge integration, decision making advantage 